IIUM JOURNAL OF EDUCATIONAL STUDIES, 2:2 (2014) 67-89

Copyright (C) IIUM Press

\title{
Early Identification and Intervention of Autism Spectrum Disorder Among Young Children
}

\section{Mastura Badzis ${ }^{a}$, Mimi Fitriana Zaini ${ }^{b}$}

\begin{abstract}
The present study focused on the paramount importance of early identification and intervention of Autism Spectrum Disorder (ASD) among young children. The focus of the study is on children with autism and their typical characters which are identified by adults. The study investigates the occurrence of Autistic Spectrum Disorder (ASD) among young children from the parents' perspective. This descriptive and analytical study aimed at finding 1) parents' perception of the need of early identification and intervention of children with autism, 2) parents' own perception of the challenges and strategies to help students with autism increase their school performance and 3 ) parents' view on strategies to help change the societal perception on ASD. There were three research questions to investigate the parents' perception in the current study; 1) the issue pertaining to the need of early identification of children with autism, 2) the questions related to useful of identification to parents, school teachers and society, 3) the questions on the challenges and strategies parents had to help ASD children receive optimal care by adults. It was found that parents identified their children behavior as ASD, regardless its degree of severity. The behaviors such as 1) emotionally unstable with bad tempered, 2) easy to be frustrated, 3) having ritual behavior, 4) quick walking habit, 5) problem with understanding, 6) reserved personality and lonely were identified with the help of the teachers in school. Strategies to help children with autism are also discussed in this paper.
\end{abstract}

Keywords: Autistic Spectrum Disorder (ASD), Identification of ASD, Intervention of ASD, Education Professionals.

a Associate Professor, Faculty of Education, International Islamic University

Malaysia, email: bmastura@iium.edu.my

b Faculty of Education, International Islamic University Malaysia 


\section{Introduction}

Recently, the number of students with autism in Malaysia is alarmingly high (Lee, 2009). According to Boyle (1996) the rapid influx of students with autism into school has presented challenges for special and general educators alike as also reported by Malaysia's Minister of Health that autism cases are on the rise into school. It is therefore a sign for teachers, educators and other responsible individuals to be alert on the importance of providing better education to both students with autism and students without ASD. Awareness on the paramount importance of early identification and intervention of ASD should be instilled for parents, teachers and other educational administrators at schools to conduct a proper learning atmosphere to students with ASD. Locally, there are about 3,000 cases of autism, with about 500 new ones diagnosed every year (Lee, 2009). In Britain, one out of every 100 students has autism, while in the United States, the ratio is 1:150 with boys are at the higher rate as compared to girls. According to Lee (2009), the ratio in Malaysia is somewhere between that of Britain and the United States. Meanwhile, according to Malaysia's Ministry of Health on the statistic on ASD, one out of 600 children in Malaysia is autistic (American Psychiatric Association, 1994) yet, in most cases, the condition is not diagnosed until much later. This number is however based on the report provided by some schools that are aware of children with Learning Disabilities (LD) especially autism, while other schools are yet pending on their reports for the uncertainty of assessment conducted (Lee, 2009).

Autism is a neurological disorder rather than psychological in nature. It does not have anything to do with behavioural problems or those behaviours that are affected or labelled as misbehaviours. The need to know the nature and characteristics of students with ASD in schools is essential as to identify their potentiality and capability of academic and non-academic performance in school. Students with ASD in schools should be treated similar to those without ASD. The characteristics of ASD can make these students both unique and challenging which are associated with providing appropriate services. These include: diagnosis (Marchand, 2002); appropriate and effective educational assessment and teaching methodology (Wolf-Schein, 1998); behavioral issues (Gomez \& Baird, 2005); communication issues (Hancock \& Kaiser, 2002); social delays and problem with interaction (Zanolli\& Daggett, 1998). 
The purpose of this study was to examine the perceptions of preschool parents regarding their experience in early detection and observation of their young children with ASD within home and school environment. The study yielded helpful information to those professional and laypersons that are responsible for early detection and identification of children with ASD. This is a vitally appropriate measure to have parents' initial steps of knowing or understanding few symptoms of ASD on their child, and they are precautious about it. It is useful for parents to provide information to others other parents whose children are autistic. This is also for the professionals to provide training and support to any programs designed to help children with learning disability especially autism. It would help teachers and other responsible educators to focus more on teaching and educational methodologies for pre-schoolers and school children with autism. The study also aimed at gathering information from the parents regarding their experience of early detection and identification of their ASD child. This appropriate initial measure can be used in the child's school, for the teachers and other responsible educators as well as the community in general to develop appropriate teaching methodology. This is also to avoid from any societal misinterpretation of the child's behaviour.

The study could be useful to serve other parents and teachers and educators as well as other professionals some fundamental research findings to develop appropriate teaching methodology as well as behavioural treatment and strategy to deal with students with autism. The study was limited to preschool parents whose child is currently 3-5 years old. The perceptions examined in the current study included the child's characteristics within home and school's setting identified by parents and helped by teachers. The child's parent was interviewed of their experience dealing with ASD child. Parent was also asked on how the preschool teachers responded on her child and how well prepared these teachers were to provide appropriate programme of/and learning adequacy for young students with ASD; and what supports the parent felt are or would be helpful to her. This study provided potentially valuable, enlightening information from the field to those who are responsible for making decisions regarding the scope and content of teaching methodology, preschool teachers' trainings to deal with learning disable students. Although the study was limited to one researcher's acquaintance only, the results may be transferable to other situations 
and settings. The research findings may also serve as a foundation for a broader investigation into the lived experiences of teachers of students with ASD.

\section{Autism: In a Nutshell}

Autism is a severe developmental disorder that affects the way a child sees and interacts with the rest of the world. It affects the child's perception and understanding on other people and it influences the way the child thinks of other people's thinking. Autism limits the child's ability to interact with others socially. Autism is a developmental disability that comes from a neurological disorder that affects the normal functioning of the brain. It is not a psychological disease, nor is it a mental dysfunction where the autistic child lost his understanding about his world. It is rather a delay in development of a child who deliberately experience difficulties in dealing and communicating with others through the usual or common communication between or among people (Gabriels, 2007). The autistic child tends to develop a theory of mind whereby the concept of understanding the communication or the conversation by others is not instilled. The child tends to interpret any activity, be it talking or playing, by using his own understanding that is usually different from others.

Autism is characterized by the unusual development of communication skills, social skills, and reasoning. Impaired communication as one core feature in autism, includes delayed or lack of functional language, impairment in initiating or sustaining conversations, stereotyped or repetitive use of language and a lack of varied, spontaneous make-believe play (American Psychiatric Association, 1994). Gabriels (2007) elaborated other features of autism to include deficits in social relatedness which relates to marked impairments in the use of nonverbal communication to regulate social interaction. This also includes impairments in peer relationship and sharing of interests or achievements. It was further elaborated that the social features by which autism is diagnosed also include difficulties appropriately initiating, maintaining and terminating social interactions, understanding the thoughts and feelings of others and perceiving the impact of one's behavior on others (theory of mind) (Gabriels, 2007). Boys are affected four times as often as females. Children may appear normal until around the age of 30 months. 
The educational institutions in the world have recognised the increased number of students with autism over the past twenty years. Different ration has been presented for this autism recognition. The US has 1:166 ratio of children with autism, while the UK has 1: 170 ratio of the autistic children (Hilman\&Synder, 2007) and Malaysia lies its ratio in between these two countries (Lee, 2009). The occurrence of autism in Malaysia has tremendously affected the perception of naïve community over throughout the country. People used to perceive this case as a mental disorder that carries the label of 'abnormality' in children with autism. Over the years, such naïve perception within the community emerges false understanding on the issue of autism and its nature. It is currently perceived as a developmental problem in a child who is normally grown up with different abilities performed in school and in his environment. On its mild end, autism ranges from a high functioning child whose ability sometimes above the average to the social disability with good listening skill yet problem in understanding and responding. On the other severe ends are those children with intellectual dysfunctions who can only be trained with assistance from the responsible adults, be it parents or education professionals.

In Malaysia, the number of students with autism in schools is undetectable. This is due to the lack of concern and attention given to the students in any school especially the International schools in Malaysia. Lee (2009) reported that for this lack of attention, their numbers remain unknown in schools. It could be due to a lack of regular public funding, or the expensive fee for the students with autism or perhaps due to the challenging characters of the students that prevents their parents to expose to the particular school. The perception of Malaysian society on the autism has somehow changed. The autistic children were previously perceived as disabled persons with mental problem are recently understood as children with developmental disability (Lee, 2009).

Hariati Azizan (2008) wrote on 'the Burden of Autism' on $28^{\text {th }}$ April in the Star online pertaining to the family pressure whose child is autistic to have to bear the extremely expensive cost for the child's treatments and therapies. She exposed the cost figure of the family with autistic child in US in a maximum of US\$80,000 (RM251, 075.12) a year. The cost that is estimated by the Autism Society of America (ASA) for the average parent or family to look after an autistic child in the United States, is lower compared to the cost spent by the Malaysian family 
whose child is autistic. It includes the needs of the modern treatments and therapies such as early intervention, physiotherapy, speech therapy, behavioural therapy and others. This cost does not yet include the family other cost of living expenses, such as transport, house rent or mortgage, food and schooling for their other children.

Since autism is also a neurobiological disorder that affects the child's communication, emotion as well as his social interaction, speech therapy becomes a very crucial treatment to reduce the problem with autistic children. These children find difficulties in talking and find ways to express their intended ideas or thought by using their own perspective according to their own world of understanding. Beside all other necessary therapies needed by the autistic children, Applied Behaviour Analysis (ABA) has been widely and usefully conducted by some practitioners. This method allows therapists to modify the behavior of the autistic child to be suited to his environment. The observable relationship between behavior and environment becomes the focus in this therapy. ABA is defined as the science in which the principles of the analysis of behavior are applied systematically to improve socially significant behavior, and in which experimentation is used to identify the variables responsible for change in behavior and is very much useful to apply for the child with autism (Brown, 2006) The approach is lent by the Behavior Learning Theory whereby all consequences of the behavior are associated with their reinforcers. The essential element for behavior modification method is depending on how the child's characters could be flexible with his environment and how the relationship of modified behavior and the setting is enhanced. By having repeated trainings of modifying the behavior, the therapy has been gaining its successful achievement not to cure autism but to normalize it to the current concept of setting.

\section{Causes of Autism}

There are numbers of researches which highlighted the issue on autism and the cause of this developmental problem in children and young adults. Over decades, researchers have been investigating the causes of autism which turned to be controversial in nature. Back in 1950s, researchers stressed upon the psychological problem that caused such disease to be appeared in public. It was a psychological factor whereby parents were believed and perceived not to develop bonding with their 
children. The attachment period which was supposed to be given by parents to their child was an absent feeling of emotion between them which caused deliberate feeling of sadness and mutism presented by the child (Bettelheim, 1956).

Environment, however, was viewed as another cause of autism. Factors such as maternal deprivation, maternal rubella, pregnancy problems on unstable emotion, irregular diet during pregnancy or obstetric complications could lead to this tremendous effect of autism (Ives \& Munro, 2002). In 1970s, there was a case of autism in a child whose mother was suffering from rubella during pregnancy (Chess et al, 1971). It was also an evidence of an autistic child whose mother was in the state of emotionally unbalanced as well as was deprived from her own mother's love, affection and care (Minett, 2005). Mother who had irregular diet problem during pregnancy was believed to have an autistic child (Ives \& Munro, 2002). The problem of obstetric complication occurred birthing process (Green at all, 1984) where hard labour could account for brain damage which in turn could be an important factor in the child's autism (Ives \& Munro, 2002).

Genetic factors and organic features somehow share common ideas on what causes autism. The genetic factors of autism emerged from the belief of the disorder which is inheritance. The hereditary factor suggests that a child is autistic due to one of his parents or grandparents who is also autistic. The study on autism by Rimland (1964) suggested that genetic played an important role in explaining autism. If one child in the family appeared to develop such problem as autism, then the other twin of him might develop that as well. Another similar study to that of nonpsychological cause of autism came from organic explanation whereby features such as learning disability and epilepsy indicated some degree of brain damage or dysfunction. Steffenburg (1991) suggested the organic features as the cause of autism whereby the child suffers from the brain damage or dysfunction that led him to be a learning disabled child in class.

The rate of autism and ASD has risen sharply in the past decade. As reported by Malaysia's Ministry of Health that autism cases are on the rise into school system. It is therefore a sign for teachers, educators and other responsible individuals to be alert on the importance of providing better education to both students with autism and students without ASD. 
Unfortunately, most cases of students with ASD are not detected until they are already in school. Therefore awareness on such important issue should be instilled in the teachers and other educational administrators at schools as to conduct a proper way of learning capability to students with ASD.

A review of current literature reflected researchers attempting to respond to this situation. The focus of this study was young children with ASD. The research showed that the characteristics of young children with ASD have been examined and discussed in the literature. One challenge noted was the need for early identification and early intervention for the students' enrolment in school in order to identify any learning disability student admitted in order to develop an appropriate early treatment to conduct for that particular student. Another problem observed was that, at societal level, majority of people are still judgmental on the issue of autism among children. The society's preference of autism labels it as something unusual occurring in the community.

The literature indicated that many positive steps were occurring in early identification by physicians and other specialists. However, there are still many misconceptions and a lack of understanding about the identification and subsequent service provision for children with ASD. The literature pointed to a need for better and more extensive training for doctors and other professionals in being able to identify the early signs of autism. Various authors within the current literature also reflected the search for school based best practices and highlighted the variety of approaches being commonly utilized.

Applied Behavioral Analysis and its accompanying techniques have been recognized as being effective with most young children (Brown, 2006). The notion that programs for children with autism must be individualized and must take each student's strengths and challenges into consideration (Brown, 2006) is considered as highly essential. There was a resounding call for scientifically based and research supported interventions. National Autism Society of Malaysia (NASOM) which was established in 1986 had established 14 Early Intervention program for children with autism (http://www.agift.my/ charity-partners/57). However, due to lack of parental concern on the benefit of early identification and intervention for their ASD child leads to misinterpretation on the child's behaviour. Both parents and teachers 
need to work hand in hand to help ASD children. Early identification and intervention help improve the potential of ASD children better in their social interaction and school performance. Therefore, for that purpose, one parent of ASD child was requested to be involved in the current study to represent other parents of any single case of autism and other learning disabled students in school or of any other experiences with the students. The information was valuable and helped to set a framework for further research in ASD children. The needs for better programs were also brought into focus.

\section{Research Methodology}

The study was conducted at the researcher's immediate environment, the neighborhood. The researcher aimed at finding the explanation and observable facts of the needs to early identify and to early intervene the strategies to help the young children with ASD. As it was reportedly evidence of the numbers of students with learning disability shown in school by the pilot research earlier, the research was expected to gain its remarkable answers for the problem of students with autism in school as well as in the society. Screening is done whenever possible, especially to those students whose documentions are not complete. Quick screening is done when there is no significant problem in the document. However, such screening policy is apparently loosely implemented by school with no specific identification of behavioural problems as well as problems in academic. The former needs clear specific guidelines in the screening system, while the later could be accepted with the letter of undertaking prepared by parents.

Nevertheless, such systematic screening system sometimes failed due to many unforeseen reasons and demand by parents, made it more difficult to follow the usual procedure of enrolment system. It is moreover a fault in the system whereby all academic problems in school such as learning disability is usually unseen and obviously is not easily detected by teachers due to inappropriate and insufficient knowledge of problems that teachers should estimate. Therefore, teachers usually have problems with the learning disabled students and do not have enough knowledge to handle the problems. Parents were asked for their evaluation. 


\section{Research Sample}

The current research focused on the parents' perception on the need of early intervention and early identification of children with autism. Parents could express their ideas on what should be the measure of intervention and identification. There are different types of measures involved for immediate detection of ASD children. However, simple measures are needed for parents, teachers as well as other laypersons in the society dealing with children with ASD. Parents are the immediate figure in ASD children's environment. They face their ASD child every day at all with attention and care. Parents are the child's provider for his immediate needs at home. This is their biological child who is having autism and this is not a disease for the parents or a punishment by the 'label' given in the society, be it in school society of the child's school environment or his society in the neighborhood. Therefore, taking parents as sample for this purpose is significant.

The current study selected the sample based on the researcher's immediate environment and friendship. The informant was a single mother with two children with one is identified as autism. The four years old child was diagnosed as having ASD by his school teacher. However, little was known to his mother on what identification of ASD is about and on what measure the child is identified as ASD by his school teacher. This identification leads to the child's withdrawn from school. Having been unsatisfied with what the teacher had diagnosed, the need to have early identification and intervention is encouraging.

The current study is obviously subjective in its nature whereby the study's focus is the perception of parents towards the need of early identification and intervention on children with autism. Perception per se involves degree of self-understanding and deep self-evaluation on any particular fact or problem in which the highest level of one's cognitive ability is assessed through a subjective yet valid and reliable method which is interview. Interview is considered as a remarkable method in qualitative research to deeply lift up the hidden insights of a particular informant. Such method allows informant to generate insights and concept as well as to expand his or her understanding on any particular issue sought. This method is generally validated by other session of interview and is meant to generalize its meaning of the concerned problem or issue to any other similar cases. 
Furthermore, Taylor and Bogden (1998) stated about the importance of having qualitative research whereby it involves individual's own expression and is valuable for the research purpose. The current study focused on the teachers' perception of the needs of students with autism which involves teachers' own experiences and thoughts towards these students. In that case, the genuine information was revealed by the teachers' world view on the matter being studied. These were thought of the teachers that should be assessed through an interview session in which thoughts were systematically expressed in accordance with research questions being asked. The current study specifically dealt with a case study which is a specific study conducted to specific individuals within a specific context. Berg (2004) described case studies as a set of research entity by knowing individual's insight in a representing environment in a specific problem at a specific location. Therefore, the current study fitted the research method selected for the purpose of assessing informants' thoughts. In this case, teachers' perception was taken into consideration for the purpose of the present research.

\section{Central Research Question and Research Questions (RQ)}

There were three research questions under one central research question which became the focus of concern in the current study on autism. The central research question was the main question to the problem being researched which was "What is autism from parent' perceptive in the context of early identification and intervention on children?" This question addressed the perception of the parents of the need to identify autism in young children which is important for children's own social development in his environment.

The RQ were specifically focused on the importance of identification on children with autism as well as the challenges and strategies developed by parents to help children with autism develop as other children too. The RQ for the current study were:

1. How do parents perceive the importance of early identification and intervention of ASD among children?

This addressed some points of elaboration on;

i) The need of early identification and assessment of ASD children is important both at home and in school. This is for the early preparation 
and helping the ASD children in both settings.

ii) How the early identification is important to support parents and teachers knowledge of ASD.

2. How do parents perceive of the usefulness of early identification and intervention of ASD among children? This question points to the following issues:

i) Parents' early identification of ASD's symptom is helpful and useful for early preparation.

ii) The perception of parents of this early identification and assessment is also useful to help teachers at school.

iii) This early identification and assessment is useful for teachers to develop awareness of giving opportunity to students with autism to participate in any program in school.

3. What challenges and helping strategies do parents have in order to help their ASD child develop like other children? It examines the following points;

i) The challenges that parents face from the characters of autistic child.

ii) Parents' feeling of efficacy to help providing supports to their ASD child.

iii) Other helping strategies that have been implementing by the parents of ASD child.

iv) The outcome of these helping strategies by the parents to perceive them as successful and methods to overcome problems arisen by ASD child.

\section{Research Procedure}

Since the current study focused on the parents' perception of the needs of students with autism, it concerned on teachers' own insight and it involved teachers willingness to be taken as sample for the purpose of study. Before the real research was conducted, there were some rationales behind considering which characters of ASD children were 
supposed to be selected for the research purposes. Based on that, the researcher set up certain requirements which were based on the parents' own knowledge and understanding of the concept of autism as well as their experience with the child. These research rationales allowed the research to conduct the research procedure systematically.

For its first step, the permission was gained from the parent herself as she was also required to observe certain aspects of the research. The selection of sample was done afterward which was based on the rationales stated. The informant was informed consent and briefed about the place and the research conducted. She was also informed about the aim of this current study as well as the teacher's diagnosed. The parent was then requested for her availability of the interview session while being briefed on the issue of autism. The day and time for the interview session were then granted by the informant.

The researcher specifically informed the informant about the flow of the interview. She was asked about her permission and willingness to have the interview session recorded by using the USB. During the interview session, the informant was also informed about the confidentiality of the information being expressed. With this information, the researcher could only begin the session of interviewing the informant. At the end of the session, the researcher expressed her gratitude for the informant's involvement in the current research. She was also ensured with the results of the study to be beneficially useful for herself as parent and other parents as well as teachers and society too.

\section{Pilot Study}

Pilot study was conducted one month prior to the real research. There was a male parent involved, whose child was exhibiting two ASD symptoms but is not yet diagnosed as an autistic child. Teijlingen and Hundley(2001) stated about the importance of doing pilot study. It is conducted to not only develop and test adequacy research instrument, designing a research protocol and assessing it to be reliable and workable, it is also to develop a research questions and research plan. The pilot study produced a good research plan and procedure so that it would be easier for the researcher to conduct a real study on the concerned matter. The pilot study was conducted in November 2012 and random questions were set up and asked to the sample. The interview was then 
transcribed to detect problems occurred during this pilot interview session. The questions set up were based on central research questions and its research questions which later on were changed drastically to suit the real research.

\section{Data Collection}

The current research was done within one and a half months starting from the end of October until the beginning of December 2012. The interview sessions were conducted in the informant's own home. Within this successful period of time, data were gathered and collected from the interview sessions with the informant. Through the interview sessions, the researcher could gain data and were analyzed accordingly to get specific results from the data analyzed. Due to the time constraints, the researcher could develop main ideas and themes from each research questions during interview sessions. The research questions were indeed based on the pilot study conducted prior to the real one, which was believed to be clear and defined in terms of information being sought. The research questions were specific to the teachers' own experiences with one population of students being research. Data were collected genuinely which were based on parent's own perception of identification and intervention of children with autism within the school and society setting. The interview session was conducted in about half an hour.

From the two interview sessions, data were gathered and interpreted to produce main ideas from each respective research questions as well as the themes were put into consideration as to summarize the whole ideas being expressed by the two informant. The themes were generated from the main ideas genuinely as the data revealed. They came from the genuine information itself which was revealed by the informant. There was no specific additional information added for the purpose of generating themes, it came directly and genuinely from the valid data gained and interpreted by the researcher throughout the interview sessions with the informant.

\section{Inter-Rater Reliability}

After the information gained and data were collected by the researcher, main ideas and themes produced from each research question to specify the results of the current study. However, the reliability procedure of the current study was taken importantly into consideration. This vital 
issue of the reliability of data revealed the truthful and fruitful results which later on to be beneficially importance and to be utilized by the school's teachers and educational professionals. Inter-rater reliability was vitally considered to rate the genuine of data from the coding of the discourse unit produced from the research questions. Therefore, there were two raters taken by the researcher for the purpose of vilifying the current research; the first rater was a colleague of the researcher who is currently pursuing her Doctorate degree at The International Islamic University Malaysia (IIUM), specializing in Industrial and Organizational Psychology, and the second rater was another colleague of the researcher who is also currently finishing her study at The Institute of Education IIUM having frequent encounter with ASD children through-out her teaching experience.

The main ideas were generated from the research questions and the selected questions of the research questions were taken by the researcher to have her own agreement on them to provide coding from the discourse units. The selected coding of the discourse unit, taken from any research questions, were given to the raters to either support or disagree with the researcher's coding. Out of the 20 total coding of the discourse unit taken by the researcher, the rater would either agree or disagree with these 20 coding of discourse unit to provide the reliability of the researcher's coding. The first rater gave her 17 coding of the discourse units while the second rater gave her 18 coding of the discourse units. Three coding of the discourse units were not put into consideration by the first rater while only two coding of the discourse units were not considered by the second rater.

The percentage of agreement between coding of the researcher and the first rater was $89 \%$ while the percentage of agreement between coding of the researcher and the second rater was $90 \%$. The total percentage of agreement from the both raters' coding was $87.5 \%$ which supported the research data as strong and reliable.

The inter rater reliability was found after the percentage of agreement of both rater's coding of discourse unit were calculated by summing up all the agreed coding of the two raters, dividing it with the total numbers of discourse unit coded and multiplying it with 100 . The $87.5 \%$ was the total percentage of the two raters' percentage of coding reliability. 


\section{Research Analysis and Discussion}

The current study aimed at findings parents' perception of the need of early identification and intervention of children with autism. The current study also aimed at looking for parents' own perception of the challenges and strategies to help the students with autism. Central research question was set up with careful observation of the problem being focused and studied. The need of early identification and intervention is important as they confirm the child's characters as those stated by DSM-IV-R. If the method was followed by parents and teachers, there should be no bias of treatment to children with autism in school.

There were three research questions highlighted into consideration in the current study. The first research question was concerned on the issue pertaining to importance of early identification of children with autism. The second one included questions related to useful of identification to parents, school teachers and society from the parents' perspective. The last research questions were put to ask teachers' perception on the challenges and strategies they had to help ASD children to receive optimal care by parents, school teachers and society.

The results of the current study were remarkably produced by the main ideas and themes generated from the three research questions. The themes generated from the first research questions were gained from its five sub-questions. These themes were obtained through the collection of the informant' information; after being coded by the researcher. The first research question was to find the importance of early identification of ASD among children from the parent's perspective. The themes generated from the first sub-question were the identification of autism, symptoms of autism and the child's traits. The themes for the second sub-question of the first research question were good English capability, writing incapability, inactive in communication. While the themes for the third sub-question were parents' importance, teachers' importance and link between teachers and parents. The themes for the fourth subquestions were society's perception and society's concern. The themes for the last sub-questions in the first research question were measure of behaviour, parents'support and teacher's consideration.

The first research question resulted in some identification of needs required by parents with ASD child. Through the interview session, parent indeed expressed her understanding on the importance of having 
early identification of children with autism. She could identify at least some symptoms of ASD on her child by explaining the different behaviour of him from others. However, she was not sure if these are the typical characters of children with autism or perhaps these are only typical kids' characters. The parent also explained about her child' participation in conversation with little eye contact and less interest which results in less active communicating though producing language and less writing ability. The parent elaborated more about the child's effort in his school's work, not only by the help of the parent, but also by the teachers' consideration. It means that children with autism could only accomplish the school's task by getting help from their parents and teachers. It showed that the student did not particularly have the independent ability on task or assignment required. This type of students was not used to have a longer period to deal with tasks. The time span was not as long as the other students with full attention paid to the tasks given.

Furthermore, the current research was also aimed at identifying the usefulness of identification and intervention of children with ASD. It was revealed from the interview session that there were some important themes to be vitally highlighted for the purpose of the results in the study. The first sub-question from the second research question produced themes such as teachers' intervention, parents' interventions, and authority's interventions. These themes discussed about the function of early detection to support children with autism not only need to involve in school's activities but also the need of varieties of interventions by adults. It was revealed that there was a need of students with autism to be involved in school activities, however, teachers need to identify certain activities suitable for the child with autism. It was also revealed that providing and developing methods of dealing with autism include as general interventions. Face to face interaction with adults' attention to the child whose eye contact appeared is also as another specific intervention.

The themes from the second research question in the current study revealed the use of early identification from parent's perspective. The early identification and intervention is very useful not only this is their right of parents or teachers to do it, but it also required society to help supporting children with ASD. The children with autism and other learning disabled group in school are at developmentally disadvantage 
according to quick evaluation by teachers and society. The use of early identification is to involve parents, teachers and society to make the children with ASD to be independent adult later in their life. The early identification is also useful for ASD children's social interaction and to build their relationship to other friends and other people in school. It is a need for their social involvement so that they could interact with people and they could get use with that interaction as often as possible to help them reduce their fear of public as one of their early symptoms of autism.

Furthermore, the needs of early identification and intervention of children with ASD should be developed in school and these would not be sufficiently fulfilled without teachers' and parents' knowledge and readiness of certain challenges they face from both the children's characters or behaviours and their usual or typical verbal and nonverbal expression. The other things that parents or teachers should necessary consider is their strategies to help children with autism. The current study also aimed at finding some challenges faced by parents of ASD child as well as their strategies to help these children. Therefore, the themes for the last research question in the first sub-question were personal emotional condition and work disturbances. It was obviously observed that these two challenges were indeed faced by the parents to deal with students with autism and other learning disabled students in school. The typical and routine act of the students such as the routine cry tantrum could simply become one challenge for the parents. Another behavioural challenge is the emotional outburst of the students as well as their sudden expression on any situation could make teachers be aware of to prepare strategies to cope and to help them in achieving their needs in school.

The second sub-question from the last research question produced themes such as teachers' support and concern, the role of counselor and homeroom teachers, role of the authority, parents' involvement and methods. The last sub-research question expected teachers' strategies to deal with students with autism as to fulfill their required needs in school. Therefore, as the themes were taken from the parents' own thoughts, the parent revealed that her strategies should accommodate students with autism and even other learning disabled students with any significant contribution and help given by educational professionals, peers and other people in school as well as in the society. The helping 
strategies expressed by parent include her own support and concern on any arisen problem by children with autism in the neighborhood. This helping strategy made parents feel related to the child and therefore, could help him willingly involve and participate in any tasks given by the teachers in school or society in his neighborhood.

Meanwhile, the role of school counselor and homeroom teachers was also regarded as another successful helping strategy to help students with autism fulfilling their needs in school. It was always expected by the school and its responsible educational agents that counselors contributes their significant help and cooperation to make students with autism and other students feel warmly and friendly environmentally accepted which later on encourages them to actively perform their ability in school. The counselors could manage the behavior and characters of this type of students and they could also cooperate with the homeroom teachers to handle any problems appeared seemly different and unusual by the students. The homeroom teachers could report on any problems created by the students to the school authority for a better solution.

Parental encouragement and involvement in their child's achievement was another helping strategy to help reduce the problems either in academic or behavior of the child at school. The school's authority reserved any right to report or to inform parents as to involve parents into the child's school achievement. Teachers or counselor or the authority of school could manage to inform parents about any tasks assigned as well as on any problems appeared. While role of the authority was expected to be the biggest contributor for helping students with autism, teachers' methods inside the classroom and outside could be another vitally important aspect to be encouraged and maintained. Teachers should understand how to deal with the students by managing different methods to be applied for the students such as by giving them extra time to do their class work or even to submit their homework. Teachers could manage to encourage and discuss more on the important aspects of $a d a b$ and values. They could talk about these aspects in class while relating to students' behaviours and characters. Besides having such good aspects in developing students' characters, a conducive environment in the society was vitally perceived as another good strategy to help students with autism fulfilling their needs in school. Teachers could create a creative decoration and comfortable classroom setting to encourage students' potential to achieve better performance in class. 
Students with autism need teachers and other education professionals to attain them and to understand their nature as well as to help them achieving their good performance in school. Therefore, such helping strategies by all the community in school were successfully implemented and continuously implemented to help students with autism.

To reiterate, autistic students often have limited language and poor social skills. They also exhibit inappropriate and repetitive behaviors, resist change, and give extreme reactions to sensory stimuli. Therefore, if these characters were identified earlier, ASD children were provided with interventions by either parents at home or teachers in school or even society in the neighborhood.

The results of observation, participant's observation were generally based on the behaviours exhibited by the child during his play time with his mother. Looking at the explanation in DSM-IV-R, the child is said to develop symptoms of autism. His repeated behaviour on playing with one object without looking at other objects is included. Anger tantrum was shown, no fear of danger was also exhibited. When the researcher gave scissors or knives to him, he showed no fear. He was not scared of the big waves approaching him. This behaviour was shown during the beach play time and the big waves approached, while other kids and even adults run away from it, the child stayed and laughed happily. Other behaviour exhibited was having intact with only one figure, in this case, the researcher's sister is the most adorable figure for him and he gets along with her and never wants to slip her hands away from him.

\section{Conclusion}

people from all walks of life must understand the nature of students with autism. They have different or unique characters as problems in their development which are not harming others. The children with autism need extra attention from other people in their environment. There are many unique ways they could exhibit in order to attract attention from parents, teachers and other people. They need teachers and parents to consider, support and help them developing themselves as other normal children and involving in the social play and other children's interaction without any interruption from parents, teachers and society due to their characters. Moreover, children with autism need to be socially accepted and appreciated. They have the rights to be involved in any social play with their peer although they seem to enjoy their own toys and are not 
scared of danger. Children with autism tend to be involved in many unintended behavior in school especially during play with friends in school and in neighborhood. They used to be labeled by some teachers and other who do not understand their nature and characters yet. These early identification and intervention should be focused in order to face challenges exhibited by children with ASD in their behavior. This should be focused by teachers, school authority, counselors, parents and other people in the community.

\section{References}

American Psychiatric Association, (1994).Retrieved from http://www. psychiatry-malaysia.org. April 10, 2013.

Berg, B. (2004). Qualitative Research Methods for the Social Sciences, Fifth Edition. Boston, MA: Pearson Publications.Batshaw, (1997). In Diana, B (2006) Teachers Perception on the needs of preschool students with autism. Unpublished doctorate dissertation submitted to the Graduate faculty of Texas Tech University: USA.

Bettelheim B. (1956). Childhood schizophrenia as a reaction to extreme situations.Journal of Orthopsychiatry 26, 507-18.

Boyle, D. (1996). The syndrome that became an epidemic. London: New Statesman.

Brown D. (2006).Teachers Perception on the needs of preschool students with autism. Unpublished doctorate dissertation submitted to the Graduate faculty of Texas Tech University: USA.

Chess S., Korn S.J., \&Fernandes P. B. (1971).Psychiatric Disorders of Children with Congenital Rubella.New York: Brunner/Mazel

DowtyT.,\&Cowlishaw K. (2002). Home Educating Our Autistic Spectrum Children.London:Jessica Kingsley Publishers.

Gabriels R., L. \& Hill D., E. (2007). Growing up with Autism. New York: The Guilford Press.

Gomez, C. \& Baird, S. (2005). Identifying early indicators for autism in self-regulation difficulties.Focus on Autism and Other Developmental Disabilities, 20(2), 101-116. In Diana, B (2006). Teachers Perception on the needs of preschool students with autism. Unpublished doctorate 
dissertation submitted to the Graduate faculty of Texas Tech University. USA.

Green W. H., Campbell M., Hardesty A. S., Grega D. M., Padron-Gaynor M., Shell J., and Erlenmeyer-Kimling L. (1984). A comparison of schizophrenic and autistic children.Journal of the American Academy of Child Adolescent Psychiatry 23, 399-409.

Hancock, T \& Kaiser, A. (2002). The effects of trainer-implemented enhanced milieu teaching on the social communication of children with autism. Topics in Early Childhood Special Education, 22(1), 39-54. In Diana, B (2006).Teachers Perception on the needs of preschool students with autism. Unpublished doctorate dissertation submitted to the Graduate faculty of Texas Tech University. USA.

HariatiAzizan (2008). The burden of autism.Sunday April 27, 2008. Download from http://thestar.com.my/news/story.asp April 10, 2013.

Hilman \& Synder, (2007) Childhood Autism: A Clinician's Guide to early Diagnosis and integrated treatment. USA: Routledge .

Ives \& Munro, (2002).Caring for a Child with Autism: A Practical Guide for Parents. London: Jessica Kingsley Productions.

Lee, T. L. (2009). Mainstreaming AutisticChildren. Sunday June 21, 2009.

Marchand, L. (2002). Autism.American Family Physician, 66(9), 1610-1612. In Diana, B (2006). Teachers Perception on the needs of preschool students with autism. Unpublished doctorate dissertation submitted to the Graduate faculty of Texas Tech University. USA.

Minett, P. (2005). Child Care and Development.Fifth Edition. . London: Hodder Arnold.

Plimley\& Bowen, (2007).Social Skills and Autistic Spectrum Disorder. London: Paul Chapman Publishing.

Rimland, B. (1964) The Etiology of infantile autism: the problem of biological versus Psychological causation. New York: Appleto-Century-Crofts.

Steffenburg S. (1991) Neuropsychiatric Assessment of children with Autism: a population based study. 'Development medicine and Child Neurology' $33,495-511$.

Taylor, S. \&Bogdan, R. (1998).Introduction to qualitative research methods: A guidebook and resource. New York: John Wiley and Sons, Chapter 4. In 
Diana, B. (2006).Teachers Perception on the needs of preschool students with autism. Unpublished doctorate dissertation submitted to the Graduate faculty of Texas Tech University. USA.

Wolf-Schein, E. (1998). Considerations of assessment of children with severe disabilities including deaf-blindness and autism.International Journal of Disability and Development, 45(1), 35-55. In Diana, B. (2006).Teachers Perception on the needs of preschool students with autism. Unpublished doctorate dissertation submitted to the Graduate faculty of Texas Tech University. USA.

Zanolli, K. \& Daggett, J. (1998). The effects of reinforcement on the spontaneous social initiations of socially withdrawn preschoolers. Journal of Applied Behavior Analysis, 31(1), 117-125. In Diana, B. (2006).Teachers Perception on the needs of preschool students with autism. Unpublished doctorate dissertation submitted to the Graduate faculty of Texas Tech University. USA. 